\title{
Teaching Third and Fourth Year Medical Students How to Cook: An Innovative Approach to Training Students in Lifestyle Modification for Chronic Disease Management
}

\author{
Benjamin Leong • Dennis Ren • Dominique Monlezun • \\ David Ly • Leah Sarris • Timothy S. Harlan \\ Published online: 11 February 2014 \\ (C) International Association of Medical Science Educators 2014
}

\begin{abstract}
Keywords Clinical nutrition · Medical students cooking
\end{abstract}

Only $27 \%$ of medical schools meet the National Academy of Sciences' recommendation of $25 \mathrm{~h}$ of nutrition instruction for medical students [1]. Despite the efficacy of physician counseling on patient behavioral outcomes, only $19 \%$ of graduating medical students are confident in their ability to provide nutrition education [2, 3]. The Goldring Center for Culinary Medicine at Tulane University addresses this disparity through one hour disease-centric seminars for third year students as well as a pioneering fourth year away rotation at Johnson \& Wales University College of Culinary Arts. These programs build on a 24-h, eight module elective available to first and second year students. While prior piecemeal student nutrition initiatives have focused on lecture format, few studies utilize longitudinal hands-on cooking classes as well with sustained institutional support [4-6]. This contrasts with The Goldring Center providing students culinary and nutrition training over 4 years with the capstone away rotation at a culinary institute. Fourth year students there spend $53 \mathrm{~h}$ in culinary classes, $53 \mathrm{~h}$ teaching clinical care insights to culinary students, and $53 \mathrm{~h}$ learning nutritional counseling strategies in lifestyle modification and medication therapy for Rhode Island Hospital-associated clinics. Students transition into this opportunity from their third year seminars that unite hands-on cooking with case studies in nutritional strategies for chronic diseases. This curriculum component in the students' final 2 years serves as the clinical translation of the classroom and community-based learning from the two preclinical years. Ongoing longitudinal analysis of school-wide surveys and national board scores are being used to assess the effectiveness of the center's curriculum from medical school into residency and clinical practice.

\section{References}

1. Adams KM, Kohlmeier M, Zeisel SH (2010) Nutrition education in U.S. medical schools: latest update of a national survey. Acad Med 85(9):1537-1542

2. Kreuter MW, Chheda SG, Bull FC (2000) How does physician advice influence patient behavior? Evidence for a priming effect. Ann Fam Med 9(5):426-433

3. Spencer EH et al (2006) Predictors of nutrition counseling behaviors and attitudes in US medical students. Am J Clin Nutr 84:655-662

4. Reporter (US). The kitchen as a classroom: medical students get a culinary education [Internet]. Washington (DC): American Association of Medical Colleges; 2012 November. https://www. aamc.org/newsroom/reporter/november2012/314006/kitchenclassroom.html. Accessed 8 Oct 2013

5. Levy J, Auld G (2004) Cooking classes outperform cooking demonstrations for college sophomores. J Nutr Educ Behav 36(4):197-203

6. Shahril MR, Wan Dali WPE, Lua PL (2013) A 10-week multimodal nutrition education intervention improves dietary intake among university students: cluster randomised controlled trial. J Nutr Metab 2013:1-11

B. Leong $\cdot$ D. Ren $\cdot$ D. Monlezun $\cdot$ D. Ly $\cdot$ L. Sarris $\cdot$

T. S. Harlan $(\bowtie)$

The Goldring Center for Culinary Medicine, Tulane University, 1430

Tulane Avenue \#8541, New Orleans, LA 70112, USA

e-mail: tharlan@tulane.edu

D. Monlezun

Tulane University School of Public Health and Tropical Medicine,

New Orleans, LA, USA 